\title{
Bounded Rationality and Tacit Knowledge in the Organizational Capabilities Approach An Assessment and a Reevaluation
}

Foss, Nicolai J.

Document Version

Final published version

Publication date:

2002

License

CC BY-NC-ND

Citation for published version (APA):

Foss, N. J. (2002). Bounded Rationality and Tacit Knowledge in the Organizational Capabilities Approach: An Assessment and a Reevaluation. The Link Program. LINK Working Paper No. 2002-18

Link to publication in CBS Research Portal

\footnotetext{
General rights

Copyright and moral rights for the publications made accessible in the public portal are retained by the authors and/or other copyright owners and it is a condition of accessing publications that users recognise and abide by the legal requirements associated with these rights.

Take down policy

If you believe that this document breaches copyright please contact us (research.lib@cbs.dk) providing details, and we will remove access to the work immediately and investigate your claim.
}

Download date: 26. Apr. 2023 


\title{
Bounded Rationality and Tacit Knowledge in the Organizational Capabilities Approach: An Assessment and a Reevaluation
}

\author{
Nicolai J Foss \\ LINK-DRUID; Department of Industrial Economics and Strategy \\ Copenhagen Business School; Solbjergvej 3, 3 ${ }^{\text {rd }}$ floor; 2000 Frederiksberg \\ Denmark; njf.ivs@cbs.dk
}

9 October 2002

\begin{abstract}
The famous three chapters in Nelson and Winter (1982) that focus on firm routines and capabilities are often taken to be solidly founded on an assumption of bounded rationality. I argue that, in actuality, bounded rationality plays a rather limited role in Nelson and Winter (1982), that the very different assumption of tacit knowledge is much more central, and that the links between bounded rationality and routines/capabilities are not clear. I then argue that the absence in Nelson and Winter of a clear methodological individualist foundation for notions such as routines, capabilities, competencies, etc. have resulted in certain explanatory difficulties in the modern organizational capabilities approach that has taken so much inspiration from their work.
\end{abstract}

\section{Acknowledgment}

The original version of this paper was written for, and presented at the DRUID Nelson and Winter conference, in Aalborg, Denmark, 12-16 June, 2001. I am grateful to Kirsten Foss for discussion of many of the issues treated herein, and to Giovanni Dosi, Sarah Kaplan, Richard Nelson, and Scott Stern for comments on an earlier version of this paper. 


\section{Introduction}

This paper discusses the respective explanatory roles of bounded rationality and tacit knowledge in the organizational capabilities approach, an increasingly influential approach to the theory of the firm that owes very much to Nelson and Winter's seminal volume, An Evolutionary Theory of Economic Change (1982). As befits a contribution to a special issue in honor of Nelson and Winter, particular attention is devoted to their much-cited treatment in chapters 3 to 5 in that book of bounded rationality and tacit knowledge in the context of firm organization and behavior - a treatment that Selten (1990: 649) characterized as having “... brought new impulses to the modeling of boundedly rational behavior in economics." However, the examination of their treatment is not just undertaken for its sake, but also because the Nelson and Winter approach to conceptualizing the firm and understanding its organization and behavior has been extremely influential for writers within the organizational capabilities approach (an umbrella term covering capabilities, dynamic capabilities, and competence approaches as well as the evolutionary theory of the firm) (see also Pierce, Boerner and Teece 2002). The organizational capabilities approach is quite often seen as an approach to the theory of the firm that puts much more of an emphasis on bounded rationality than is the case in, notably, transaction cost economics (e.g., Fransman 1994; Conner and Prahalad 1996; Marengo et al. 2000). It is also seen as one that goes beyond information-processing and stresses the tacit and socially embedded aspects of knowledge (Fransman 1994). Both of these characteristics hark directly back to Nelson and Winter.

In this paper I engage critically with this influential view. Specifically, the following points are developed. First, the argument is made that the theory of firm developed in Nelson and Winter (1982) is considerably less about bounded rationality than it is about socially held tacit knowledge. Bounded rationality and tacit knowledge do not logically imply each other. It may, in fact, be argued that Simonian bounded rationality and Polanyi's notion of tacit knowledge are ultimately founded on very different, and perhaps incompatible epistemologies (see Nightingale 2002). Attempts to combine the two are likely to be unsuccessful, one driving out the other. 
This is largely the case in Nelson and Winter (1982), in which tacit knowledge looms much larger than bounded rationality. The tip of balance in favor of tacit knowledge has become even more pronounced in subsequent work within the organizational capabilities approach. Second, the emphasis on socially held knowledge in the form of "routines" and the downplaying of bounded rationality in Nelson and Winter (1982) mean that there is very little attention to the level of individual agent. Indeed, the Nelson and Winter theory (as well as many subsequent contributions to the organizational capabilities approach) may be criticized for not being consistent with methodological individualism, at least in the sense that it works with aggregate entities (i.e., routines and capabilities) that are not explicitly reduced to individual behavior. Third, I argue that the absence of a clear behavioral foundation for the organizational capabilities approach is the root cause of the difficulties that the organizational capabilities approach has with respect to illuminating the key organizational economics issues of the internal organization and boundaries of the firm.

\section{Nelson and Winter (1982): a High Point in the Evolution of the Organizational Capabilities Approach}

\section{Briefly on the Organizational Capabilities Approach}

What I here call the "organizational capabilities approach" gets its name after chapter five in Nelson and Winter (1982) (cf. also Dosi, Nelson and Winter 2000). Nelson and Winter (1982) has arguably appealed more to business administration and management (particularly strategy) scholars than to economists. ${ }^{1}$ One paper after another, in such fields as strategy, organizational learning, international business, and organizational behavior, have generously cited the book, particularly the three chapters ( 3 to 5 ) that deal with issues pertaining to individual and organizational behavior and capabilities. This is not surprising: Re-reading the chapters makes one realize that perhaps not so much essential has happened in two succeeding decades of work on capabilities, competence, evolutionary, etc. theories of the firm that goes

\footnotetext{
1 See the citation analysis in Meyer (2001).
} 
beyond Nelson and Winter's treatment. It is arguable that later ideas on competence traps, the central importance of tacit and socially complex "resources" for explaining competitive advantage, knowledge replication, and dynamic capabilities can be found in at least an embryonic, and often quite explicit, form in Nelson and Winter (1982).

Quite appropriately, contributors to the organizational capabilities approach have therefore often treated Nelson and Winter (1982) not only as a source of inspiration, but also as a foundation. At first sight this may appear somewhat surprising, given that building a distinct theory of the firm was never the intention of Nelson and Winter (1982). ${ }^{2}$ However, what may appeal to writers within the organizational capabilities approach is the attempt in that book to treat in a unified fashion bounded rationality and tacit knowledge, and at the same time place these in a social context - all of which converges in a single, highly intuitively plausible concept, namely that of "routine." These ideas, as well the use of them to help explaining revealed competitive advantages, innovation and limited aspects of economic organization, cannot really be found in any other of the precursors of the capabilities approach. Thus, what unites recent capabilities (Richardson 1972; Chandler 1992; Langlois 1992), dynamic capabilities (Teece and Pisano 1994), competence approaches (Sanchez 2001), the knowledge-based view of the firm (Fransman 1994; Grant 1996), and, of course, the "evolutionary theory of the firm" (e.g., Marengo et al. 2000; Dosi 2000) is indeed an emphasis on the central explanatory importance of experiential, localized, socially constructed and embedded knowledge and learning in understanding firm organization and behavior.

As Langlois and Foss (1999) point out, these approaches are also united in their attempt to increasingly go beyond their traditional explananda of explaining the sources of competitive advantage, localized innovative activity, and general rigidity of firm behavior to also include issues, notably the boundaries and internal organization of the firm, that have traditionally been considered the turf of the more

2 At the Academy of Management Meetings in Toronto, August 2000, Sidney Winter, in a major address, insisted that there is no theory of the firm in Nelson and Winter (1982). Presumably, what he meant is that there is no theory of the firm in the sense of explaining the existence and boundaries of the firm. 
mainstream economics of organization. At the heart of these stories are the characteristics, notably tacitness, of the knowledge that is embedded in organizational capabilities (Kogut and Zander 1992; Langlois 1992). Some (vaguely specified) mechanism is supposed to link these characteristics to the boundaries of the firm as well as to aspects of internal organization.

It is quite common to interpret this literature as an attempt to provide more room for bounded rationality than is standard fare in the economics of organization (e.g., Conner and Prahalad 1996; Fransman 1994). However, it is seldom made clear in exactly what sense the organizational capabilities literature may be characterized as starting from bounded rationality. Because bounded rationality is, unfortunately, a concept that comes with an legacy of diverse and even conflicting interpretations, it does matter where exactly one starts from, and it is rather uninformative to say that the organizational capabilities approach builds on bounded rationality, unless one specifies what kind of bounded rationality. Thus, are we talking about Newell and Simon's work on heuristic search, or Selten's aspiration adaptation theory, or Lipman or Rubinstein's axiomatic foundations for bounded rationality, or regularities established in experimental psychological research, or another one of the great number of different — indeed, very different — variations on Simon's Grand Theme?

However, such information is virtually never forthcoming. Indeed, it is easy to become skeptical about the real role played by bounded rationality in the organizational capabilities approach for the basic reason that out of the many sources that the approach builds on, notably the works of Philip Selznick, Alfred Chandler, Edith Penrose, G.B. Richardson and Nelson and Winter (1982) (see Foss 1997 for a sampling), only Nelson and Winter explicitly address and try to incorporate bounded rationality. ${ }^{3}$ All this raises suspicions that talk of bounded rationality in connection with the capabilities approach may in actuality be more rhetorical (in the preMcCloskeyan, derogatory sense) than substantive. Understanding the extent to

\footnotetext{
3 It may be argued that behavioralist organization theory (notably March and Simon 1958 and Cyert and March 1963) is also a key input into the development of the approach (Pierce, Boerner, and Teece 2002 present such a reading). However, this is quite unusual, and not everybody would agree. For example, Fransman (1994) argues that behavioralism is taken up with information-processing whereas the real concern in the organizational capabilities approach is the use and growth of knowledge. The present paper leads to support Fransman's rather than Pierce, Boerner and Teece's position.
} 
which the organizational capabilities approach builds on a foundation consisting of bounded rationality requires that we take a look at Nelson and Winter, precisely because this contribution has been hugely influential with respect to the conceptualization of business firms as well the understanding of their organization and behavior.

\section{Nelson and Winter on Skills, Routines, and Organizational Behavior}

Quite early in Nelson and Winter (1982), namely when discussing "the need for an evolutionary theory," the authors observe that their "... basic critique of orthodoxy is connected with the bounded rationality problem" (p.36), and that, therefore, they “... accept and absorb into our analysis many of the ideas of the behavioral theorists" (p.35-36), notably Cyert, March and Simon. In particular, they are attracted to the behavioralist notion that short and medium run firm behavior is determined by relatively simple decision rules (Cyert and March 1963). ${ }^{4}$ They also make use of behavioralist models of satisficing search (Simon 1955). In a later contribution they note that " $[\mathrm{t}]$ he view of firm behavior built into evolutionary economic theory fits well with the theory of firms contained in modern organization theory, especially the part that shares our own debt to the 'Carnegie School' (March and Simon, 1958; Cyert and March, 1992)" (2002: 42). However, in the 1982 book Nelson and Winter go significantly beyond behavioralism by examining populations of firms with differing decision rules, by addressing the interplay between changing external environments and changing decision rules (see also Pierce, Boerner and Teece 2002), and, the most interesting theoretical innovation in the context of this paper, by trying to bring bounded rationality together with tacit knowledge. It is the last aspect of Nelson and Winter's "updating exercise" that I shall argue is not entirely successful.

Nelson and Winter's main problem with "orthodox" theory, and particularly the neoclassical theory of the firm, does not appear to be that this theory rules out diversity in terms of productive or organizational capabilities between firms in an industry per se (as some contributors to the organizational capabilities approach have

4 Winter (1964b) wrote an early and favorable review of Cyert and March (1963). In a later paper (Winter 1986), he was quite explicit about the behavioral nature of the theory in Nelson and Winter (1982). However, behavioralism is only one among a large set of inspirations and precursors. 
argued, e.g., Conner 1991). Indeed, that theory does allow for variety in these dimensions. For example, to the extent that differences in how well ("competently") a firm is run reflects owners' on the job consumption, and these owners are able and willing to bear the consequences of this consumption (Demsetz 1997), the neoclassical theory of the firm allows for differential competencies to exist in equilibrium. One may also simply postulate differential initial endowments of some costly-to-copy resources, so that firms with differential efficiencies may exist in equilibrium. However, the main point of Nelson and Winter's critique is that in mainstream economics, heterogeneity is at best exogeneously determined (as in the cases of differing preferences for on the job consumption or different initial endowments). To paraphrase their argument, in the setting of the (basic) neoclassical theory of the firm, it has to be in this way, because the production set is assumed to be not only given (or at best changing through given technological progress functions or similar constructs), but also to be fully transparent. The implication, as Demsetz (1991) notes, is that if information costs are thus assumed to be zero, what one firm can do on the level of production, another firm can do equally well.

Unlike Demsetz, Nelson and Winter do not cast their argument in terms of the information (and other) costs of copying rival firms' resource endowments. Instead, they devote a whole chapter (4) to an analysis of skills. By a skill, they mean "... a capability for a smooth sequence of coordinated behavior that is ordinarily effective relative to its objectives, given the context in which it normally occurs" (1982: 73). The attractions of the notion of skill are apparent. First, it provides a way of introducing dynamics on the level of production, since skills need to be nurtured and tend to grow with practice. Second, it provides an analogy to the behavioralist notion that behavior is strongly guided by relatively rigid decision rules, and thus serves to underscore Nelson and Winter's critique of maximization in the sense of forwardlooking, informed deliberate choice. They put much emphasis on this, noting that "...the sort of choice that takes place in the process of exercising a skill is choice without deliberation" (p. 82), although they are careful to note that the behavioral "programs" embodied in skills may be initiated through deliberate, but presumably boundedly rational, choice. However, this and the notion that routines may be 
changed through meta-routines (i.e., search routines) is the only substantive connection that the notion of bounded rationality make to skills and the organizationlevel counterpart to individual skills, namely routines. Neither concept is directly derived from from bounded rationality considerations. Third, starting from skills and developing the organization-level analogy to skills allow Nelson and Winter to bring considerations of tacit knowledge into the picture and to develop a strong critique of the "blueprint" view of neoclassical production function theory. Fourth, it helps them to establish a link between individual action and organizational behavior. That link is initiated in a rather straightforward way by the observation that "... directly relevant to our development here is the value of individual behavior as a metaphor for organizational behavior" (1982: 72; emphasis in original).

In turn, "organizational behavior" is addressed in terms of "routines" that serve as organization-level metaphorical equivalents to individual skills. Note in passing that this is not an idea that originates with Nelson and Winter (1982). Thus, Simon (1947) argued that habit may be understood in terms of limits to attention'; in turn, habit has an organization-level counterpart, namely organizational routines. Like skills, routines represent stable sequences of actions (i.e., they coordinate actions) that are triggered by certain stimuli in certain contexts and which, in a sense, serve as memories for the organizations that embody them. However, because routines are social phenomena, they go beyond the skill metaphor and raise issues of motivation and coordination. However, Nelson and Winter sidestep the motivation issue, arguing that routines represent "organizational truces," an idea going back to Cyert and March (1963).

Thus, quite a lot - and perhaps too much — is packed into the notion of routine, including a variety of behaviors (e.g., heuristics and strategies), organizational processes and arrangements, cognitive issues (e.g., "organizational memories"), and incentives ("truces"). ${ }^{6}$ Nelson and Winter defend this by noting

\footnotetext{
${ }^{5}$ Nelson and Winter (1982: 85) are hinting at a similar idea when they observe that "... there is in a sense a tradeoff between capability and deliberate choice, a choice imposed ultimately by the fact that rationality is bounded." This attempt to explain skills in terms of attention allocation is, however, not extended to the level of routines.
}

${ }^{6}$ See also Winter (1986: 165) for a sophisticated further discussion and defence of this. 
that, in actuality, “... skills, organization, and 'technology' are intimately intertwined in a functioning routine, and it is difficult to say where one aspect ends and another begins" (1982: 104). Although it is true that the boundaries are blurred, it is not clear why one is not excused, for purposes of analytical clarity, to look at one aspect at a time. It is one thing to claim that ontologically, things are a mess. It is another thing to openly admit the mess into analysis. This is perhaps only a minor problem for Nelson and Winter: Because their level of analysis lies higher than the firm, they can afford to keep the firm level messy. However, their all-inclusive notion of routine may have contributed to the considerable terminological soup that characterizes the organizational capabilities approach as well as the difficulties of giving precise content to the notion of routines (cf. Cohen et al. 1996), and derived and related notions, such as capabilities, competencies, etc. In the following, another possible source of conceptual and explanatory problems in the organizational capabilities approach is considered, namely the absence of a clear foundation, rooted in individual, boundedly rational choice behavior, for the notion of routines.

\section{A Closer Look on Bounded Rationality and Tacit Knowledge in the Organizational Capabilities Approach}

At first glance, bounded rationality appears to be quite crucial to Nelson and Winter's argument (Fransman 1994). Thus, firm members can only learn routines through practicing them; routines are simply repeated until they become too dysfunctional; learning is myopic, search is satisficing; etc. All of these very strong assumptions about individual and organizational behavior would seem to make room for a rationality that is very bounded indeed. Apparently, this is Williamson's impression when he argues that Nelson and Winter work with a version of bounded rationality, "organic rationality," that assumes less intentionality, foresight and calculativeness than his own notion of bounded rationality (Williamson 1985: ). However, (re)reading chapters 3 to 5 in Nelson and Winter suggests that what ultimately interests them is not really bounded rationality per se in the sense of a commitment to building specific models of boundedly rational individual behavior that, in turn, may 
be fed into models of organization level behavior and outcomes. What interest them is rather tacit knowledge and its embodiment in their firm-level analogy to individual skills, namely routines, and how these notions assists the understanding of sluggish organizational change and adaptation. These claims are substantiated in the following.

\section{The Limited Role of Bounded Rationality in Nelson and Winter}

Bounded rationality has a bad reputation for being used as a sort of catch-all category that can "explain" all observed deviations from maximizing rationality (Conlisk 1996; Casson and Wadeson 1997). The Simon dictum that man is "intendedly rationality, but only limitedly so" is an example. In itself it is vacuous and therefore explains or predicts virtually nothing. Explanation and prediction that begins from a foundation of bounded rationality requires that bounded rationality be focused through specific models of behavior (such as Simon 1955). This is where the link to the skill metaphor of organizational behavior becomes important, for it is the use of the notion of skill and particularly its transfer to the organizational level that step in and fill the explanatory and predictive vacuum left by invoking bounded rationality in general terms. In other words, it is skills and, particularly, routines that allow Nelson and Winter (1982) to work out an explanatory and predictive theory of firm behavior. However, the additional assumptions that are added to the basic invocation of bounded rationality are not drawn from the existing evidence, notably from psychology, on boundedly rational behavior per se, although Nelson and Winter (2002: 31) in a later paper argue that " $[\mathrm{I}] \mathrm{n}$ contrast to the usual quest for microfoundations in economics, seeking consistency with rationality assumptions, our quest is for consistency with the available evidence on learning and behavior at both the individual and organizational levels."

In fact, it turns out that what they mean by the "available evidence" may be somewhat idiosyncratic. They go on to argue, in the 2002 paper, that " $[\mathrm{w}] \mathrm{ith}$ respect to individual learning, the plausibility of our behavioral foundations for evolutionary economics has received support from an unexpected quarter. Studies linking cognitive abilities and brain physiology have established the existence of 
anatomically distinct memory processes supporting the skilled behaviors of individuals" (Nelson and Winter 2002: 33). ${ }^{7}$ Not only is such memory "highly durable," it also "... functions in some ways that are alien to theories of calculative rationality" (p.34). While this cognitive science support for the notion of skilled behavior seems compelling, the evidence they present in support for the critical move from individual skilled behavior to the organizational, routine level is less so. The only cited evidence is an experimental study of card-playing teams (Cohen and Bacdayan 1994) that demonstrated that team level skills (i.e. "routines") aquired under one specification of the played game made the adaptation to a new specification of the game sluggish. While this has much with skilled and inertial behavior and problems of adaptability on the level of teams, it is not clear what exactly all this has to do with bounded rationality. Thus, Nelson and Winter's (2002) recent stocktaking reinforces the tendency in Nelson and Winter (1982) to lump together an almost empty characterization of bounded rationality with a much richer description of skilled behavior. Bounded rationality is, in effect, suppressed as a result of this exercise. This raises the question of why bounded rationality is treated as a background assumption while individual and organizational level skilled behavior takes precedence.

\section{Why Tacit Knowledge is More Important than Bounded Rationality in Nelson and Winter}

Nelson and Winter (1982) explicitly compare skilled behavior to the execution of a computer program. ${ }^{8}$ The outcomes of computer programs are predictable, given knowledge of what is fed into them and knowledge of the program itself. When triggered in a certain context, skilled behavior is also predictable, and knowledge of an individual's skill set, the relevant context, and the relevant stimulus may also allow for reasonably accurate prediction of his behavior. Per implication, if

\footnotetext{
${ }^{7}$ No references are given, but presumably they have in mind the kind of work described in Damasio (1994).

${ }^{8}$ Winter's background at RAND may have played a role here: It was a commonly held view at RAND that the computer is a "scale free" model of organization. If both organizations and skills can be characterized in terms of computer programs, the metaphorical jump from skills to the organizationlevel of routines seems tempting to make - and may actually be more than merely metaphorical.
} 
organizational routines, the organization-level counterpart to individual skills, also may be understood as programs that make aggregate (i.e., organization-level) behavior predictable and inert. And it is inert organizational behavior that Nelson and Winter (1982) are after, because this is a necessary part of their evolutionary mode of explanation. Thus, tacit knowledge, as embodied in skills and routines, can do the job. ${ }^{9}$ Can bounded rationality do the job, that is, can it explain inert organizational behavior?

In Nelson and Winter, bounded rationality is mainly treated to the extent that it provides an underpinning for the behavioralist notion of decision rules, particularly in connection with search. Such decision rules may be understood as manifestations of bounded rationality, on the individual level (cf. Simon 1955) and, less obviously, on the organizational level (Cyert and March 1963). One may expect rule-bound behavior to also provide a strong explanation of inert organizational behavior. However, there are two reasons why bounded rationality and the decision rules it gives to may not be a strong foundation for a theory of organizational inertia. First, decision rules that are explicit (i.e., Cyert and March's 1963 "standard operating procedures") may arguably be changed at lower cost than complex routines that embody huge amounts of tacit knowledge. In this sense, routines that are rationalized in terms of skills and tacit knowledge offer a stronger explanation of organizational sluggishness than standard operating procedures. Tacit'ness beats bounded rationality with respect to the explanation of inertia, as it were. Second, it is far from clear that individual bounded rationality produces inert behavior on the aggregate level. To be sure, such stories can be told (e.g., Heath, Knez and Camerer 1993; Egidi 2001), but they require that bounded rationality and the interaction between boundedly rational agents be specified in certain ways. To take an almost trivial example, if similar agents all suffer from status quo-biases, their aggregate behavior may indeed manifest inertia. In contrast, it is not clear that inert aggregate

\footnotetext{
${ }^{9}$ In fact, tacit knowledge can do the job so well that it is not clear that Nelson and Winter even need bounded rationality for the purpose of understanding such adaptation. For example, if organizational members do not hold the same tacit knowledge, this may be sufficient to explain sluggishness, because of costly communication.
} 
behavior will in general follow from individual level rule-following, for example, in the form of some satisificing model.

Thus, bounded rationality alone cannot do what Nelson and Winter wish their behavioral assumptions for them; hence, the invocation of skills, and the use of the skill metaphor to address aggregate behavior. In the end, bounded rationality is more a sort of background argument that — inspiring other assumptions about tacit knowledge and skilled human behavior - serves to make plausible the notion of organizational routine (including search routines), and therefore the sluggish organizational adaptation that is crucial in Nelson and Winter's evolutionary story. ${ }^{10}$ Thus, the whole construct works from an initial argument about bounded rationality, goes from there to behavioralist decision rules, jumps via analogy to ideas on tacit knowledge as embodied in skilled behavior, and then transfers skills to the level of routines and organizational capabilities. Bounded rationality re-enters the story when changes in routines and capabilities have to be explained, namely in the form of dynamic search routines.

This is a complicated exercise that has some unfortunate consequences. In addition to the various problems identified in the Cohen et al. (1996) symposium on the meaning of routines, there are at least two further problematic consequences of this exercise. First, tacit knowledge and bounded rationality tend to become indiscriminately lumped together, because it is not transparent where the one ends and the other begins. Of course, tacit knowledge and bounded rationality are different things and do not necessarily imply each other. Thus, there can be tacit rules for maximization, as Machlup (1946) argued. Or, agents can cope with bounded rationality by means of fully explicit operating procedures. While one can certainly construct an argument that boundedly rational agents make use of experientially

\footnotetext{
${ }^{10}$ Moreover, those who are not committed to behavioralism may point out that even if one wishes to keep organizational routines central, it is not so obvious how essential bounded rationality really is. This may be argued in a number of ways. One can have perfectly rational standard operating procedures. It is possible to tell a story in which different routines in a population of firms emerge as solutions to appropriately specified games being played in each firms and with agents acting in a maximizing manner. Search behavior is easily reconciled with maximization. It is perfectly possible to tell sophisticated maximization stories about agents following rigid routines and procedures, once a full account is made of all relevant costs (e.g., costs of memorizing, depositing, retrieving, etc. information) (Casson and Wadeson 1997; Foss and Foss 2000).
} 
produced - and "skilled" - decision rules that are likely to embody a good deal of tacit knowledge (Langlois 1999), there is no necessary connection between bounded rationality and tacit knowledge. Second, and perhaps more seriously, bounded rationality on the level of the individual becomes suppressed. This makes it hard to understand the link between bounded rationality on the one hand and routines and other organizational phenomena on the other. In other words, what exactly is the nature of the mechanism that aggregates from individual behavior to routines and organizational behavior? This mechanism is never really identified in Nelson and Winter (1982). ${ }^{11}$ It also means that there is a certain interpretative ambiguity surrounding the notion of routines to the extent that it is related to bounded rationality: Is organization-level routinization produced by interaction effects among the members of a team or is it ultimately founded in aspects of individual cognition (Egidi 2000: 2). These issues are not resolved in Nelson and Winter (1982). In fairness, it should be noted that this is perhaps not surprising, since rather little work existed on this issue when Nelson and Winter wrote their book.

\section{The Organizational Capabilities Approach and Economic Organization}

As mentioned earlier, Nelson and Winter (1982) is a high point in the development of the organizational capabilities approach, and their work has been foundational for much subsequent work within this approach. It has also been mentioned that the modern organizational capabilities approach aspires to being a theory of economic organization, a point where it goes beyond Nelson and Winter (1982). The argument that will be briefly developed here is that certain characteristics of Nelson and Winter (1982) were carried over into the organizational capabilities approach, characteristics that may not be so problematic if the analytical purpose is one of explaining rigidity in firm behavior as a part of a broader evolutionary story, but which are much less appropriate for the purpose of building a theory of economic organization. ${ }^{12}$ The relevant characteristics are a strong emphasis on aggregate

\footnotetext{
${ }^{11}$ Later work in the evolutionary economics is less vulnerable to this critique, notably the work of Egidi (e.g., 2000), Marengo et al, (2000), Warglien (e.g., 1995), and Dosi, Marengo, and Fagiolo (1996).

${ }^{12}$ Foss (1996) discusses other problems with organizational capabilities theories as theories of economic organization.
} 
entities, notably routines and organizational capabilities, an emphasis that comes at the expense of attention to individual behaviors, and derives from Nelson and Winter's attempt to establish a metaphorical solution to the aggregation problem of moving from the level of the agent to the level of the organization. ${ }^{13}$ Because they fully recognize the metaphorical character of this maneuver, they do not commit the mistake of conflating an ontological claim with a useful research heuristic. Later contributors to the organizational capabilities approach may not have been as careful here as Nelson and Winter.

Problems seem to emerge rather unavoidably as soon as Nelson and Winter's ideas on organizational routines and capabilities are transferred from their original place in the analysis of a changing population of firms to an analysis of the behavior and, particularly, organization of individual firms. While these notions have indeed been of value for the understanding of, for example, the sources of competitive advantage (although much of this literature is also plagued by conceptual ambiguity), their application to economic organization is more problematic. For example, the much cited Kogut and Zander (1992) paper essentially argues directly from the tacit knowledge embodied in organizational capabilities to the boundaries of the firm. The supporting argument is that "firms know more than their contracts can tell". However, there is no attempt to address this is in terms of comparative contracting, and, ultimately, individual behavior. What exactly is it that cannot be written in contracts? Even if writing costs in fact are prohibitive, why cannot relational contracting, involving highly incomplete contracts, between independent parties handle the transfer of knowledge? Why is it only vertical integration that economizes with what are presumably writing and communication costs? No compelling answers are given to such questions. This is the case of most of this literature as it applied to economic organization. A partial exception is the work of Langlois (1992). Langlois attempts to supply the missing mechanism from organizational capabilities to the boundaries of the firm by means of the concept of "dynamic transaction costs,"

13 A doctrinal history corollary to this argument is that Nelson and Winter's theory of the firm capabilities and behavior is more in line with the thinking of Thorstein Veblen and prehaps Friedrich Hayek than wit the behavioralist tradition that they see as among the most important precursors of their work. On Veblen as a precursor of the organizational capabilities approach, see Foss (1998). 
which are essentially communication costs that arise because of "dis-similar" (Richardson 1972) capabilities in a vertical structure of firms. Presumably efficient economic organization minimizes such costs (as well as other more "traditional" transaction costs, allowance being made for possible tradeoffs between these).

However, this idea may imply another difficulty, one that is also present in Nelson and Winter (1982) and in virtually all of the organizational capabilities literature. This difficulty is that knowledge inside firms is assumed be homogenous (or less strongly: Not very costly to communicate), while knowledge between firms ("differential capabilities") is taken to be (very) heterogeneous (and therefore costly to communicate). Thus, Winter (1986: 175) assumes that “... the search for information from external sources does not proceed with the same ease as for internal sources." If this were not the case, it is hard to see how communication costs could carry implications for the boundaries of the firm. However, although there may be some intuitive appeal to the assumption, it is hard to accept as true in general. There are many examples of firms where the bandwidth of the communication channels between some business unit of the firm and external firm (e.g., buyer or seller) is much higher than the bandwidth between the unit and, say, corporate headquarters. Moreover, the implicit assumption that knowledge in hierarchies can be taken, at least as a first approximation, to be communicable at zero cost makes it hard to understand hierarchical organization, since with zero cost communication the managerial task has no economic rationale (Demsetz 1991; Casson 1994).

\section{Methodological Individualism}

It seems fairly obvious that the essentially ad hoc assumptions that knowledge inside firms can be communicated at low costs while knowledge between firms can only be communicated at high cost slip into the analysis when the units of analysis are routines or organizational capabilities. It is then easy to postulate that "firms know more than their contracts can tell" and that all organizational aspects are "intertwined in a functioning routine." If instead the analysis had started in an explicit methodological individualist mode, that is, from individual choice behavior, the argument that communication costs within, for example, certain business units 
may be lower than the communication costs between people in the unit and people in a supplier firm, might have been derived as an outcome of a properly specified model instead of being postulated. ${ }^{14}$ The problem is that there is no theory of individual choice behavior in the organizational capabilities approach, so that writers in the organizational capabilities approach have to treat economic organization in a methodological collectivist way, namely in terms of postulating somewhat crude causal relations between capabilities and economic organization, little attention being paid to the microanalytic issues involved. Not surprisingly, these stories are vulnerable to basic critiques from the perspective of comparative contracting (Foss 1996; Williamson 2000).

Ironically, it turns out that much of the organizational capabilities approach is vulnerable to the same critique that Winter (1991) forcefully (and justifiably) launched against the neoclassical theory of the firm. Specifically, and borrowing directly from Winter, it is in potential "conflict with methodological individualism" (p.181) (because of the emphasis on routines and organizational capabilities), “... provides no basis for explaining economic organization" (p.183) (because transaction costs and comparative contracting are not considered), lacks "realism" (because of its "unrealistic" treatment of decision-making as entirely guided by routines), and provides a "simplistic treatment of its focal concern" (e.g., because it is simply assumed that it is easier to gather, combine, source, etc. knowledge inside firms than between firms). The main underlying problem, it has been argued here, is that too little attention is devoted to individual decision-making. The problem goes at least partly back to Nelson and Winter: It is arguable that their side-stepping of bounded rationality on the level of the individual agent in favor of aggregate notions (i.e., routines and capabilities) is an important source of some of the explanatory difficulties that the modern capabilities approach confront.

\section{Concluding Comments}

${ }^{14}$ For what I have in mind here, see, for example, Barr and Saraceno (2002) and Zandt (1999). 
In conclusion it appropriate to cast the argument in this paper in a somewhat broader context. In a fine paper, Paul Nightingale (2002) has made an argument that is parallel to the one that has been developed. Nightingale (2002: 1) argues that Nelson and Winter (1982) seek to “... bring together two very different ways of thinking about knowledge," namely the more appreciative "... tacit knowledge tradition that derives, in part, from Polanyi's phenomenology" and the more formal "... objectivist information processing, problem-solving approach that derives, in part, from Simon." This is visible in their attempt to conceptualize firms both in terms of information processing and in terms of tacit and socially embedded knowledge. Nightingale argues that a number of tensions in the science and technology policy literature are traceable to this problematic attempt in Nelson and Winter to fuse two epistemologies, the tensions between which are what has fuelled other recent debates, notably in artificial intelligence research.

Much of the argument in this paper may be cast in similar terms: The attempt in Nelson and Winter to combine ideas on routines and skilled behavior that are derived from Polanyi with ideas on bounded rationality and satisficing search that are derived from Simon has not been entirely satisfactory, and may be an important source of some of the explanatory difficulties that confront the modern organizational capabilities approach. An indication that Nelson and Winter's reconciliation exercise was not entirely successful is that tacit knowledge and bounded rationality simply are not equal partners in the 1982 book; the three central chapters on firm organization behavior and organization are to a much larger extent about tacit knowledge than about bounded rationality. Thus, contrary to a commonly held view, the role of bounded rationality in the organizational capabilities approach is very much a background one. ${ }^{15}$ Its precise relation, if any, to the notion of the central concepts of routine and capability is unclear. Its role seems more rhetorical than substantive. At any rate, boundedly rational behavior on the level of the individual agent is not modeled, neither in Nelson and Winter's seminal 1982 book, nor in the

15 For the parallel argument that the role of bounded rationality in the modern economics of organization (notably transaction cost economics) is also a background one, see Foss (2001). 
many contributions to the organizational capabilities approach that are so heavily indebted to this contribution.

Finally, lest this paper be taken as a general attack on the organizational capabilities approach, it is important to stress that its real message is a methodogical one: Writers in the organizational capabilities tradition should devote more analytical energies to getting the microfoundations right. It will not do in the long run to continue working with concepts whose microfoundations are unclear. This is not just a matter of conforming to the conventional methodological individualist approach of most of economics. It is also, and more substantively, a matter of the explanatory and predictive capabilities of the organizational capabilities approach being less impressive than they could be as a result of the lack of microfoundations for concepts such as routines, capabilities, etc. 


\section{References}

Barr, Jason and Francesco Saraceno. 2002. "A Computational Theory of the Firm," Journal of Economic Behavior and Organization 49: 345-361.

Casson, Mark. 1994. "Why Are Firms Hierarchical?," International Journal of the Economics of Business 1: 43-81.

Casson, Mark and Nigel Wadeson. 1997. "Bounded Rationality, Meta-Rationality, and The Theory of International Business," Working Paper No. 242 (Discussion Papers in International Investment and Management), Dept. of Economics, University of Reading.

Chandler, Alfred D., Jr. 1992. "Organizational Capabilities and the Theory of the Firm," Journal of Economic Perspectives 6: 79-100.

Cohen, Michael and Paul Bacdayan. 1994. “Organizational Routines are Stored as Procedural Memory," Organization Science 5: 554-568.

Cohen, Michael D., Roger Burkhart, Giovanni Dosi, Massimo Egidi, Luigi Marengo, Massimon Warglien and Sidney Winter. 1996. "Routines and Other Recurrent Action Patterns of Organizations: Contemporary Research Issues," Industrial and Corporate Change 5: 653-698.

Conlisk, John. 1996. "Why Bounded Rationality?," Journal of Economic Literature 34: 669-700.

Connor, Kathlyn R. 1991. “A Historical Comparison of Resource-based Theory and Five Schools of Thought Within Industrial Organization Economics: Do We Have a New Theory of the Firm?," Journal of Management 17: 121-154.

Connor, Kathlyn R. and C.K. Prahalad. 1996. "A Resource-based Theory of the Firm: Knowledge vs. Opportunism," Organization Science 7: 477-501.

Cyert, Richard M. and James G. March. 1963. A Behavioral Theory of the Firm. Englewood Cliffs: Prentice Hall.

Damasio, Antonio R. 1994. Descartes' Error: Emotions, Reason, and the Human Brain. New York: Grosset/Putnam.

Demsetz, Harold. 1991. "The Nature of the Firm Revisited," in Oliver E. Williamson and Sidney G. Winter, eds. 1991 The Nature of the Firm: Origins, Evolution, and Development. Oxford: Basil Blackwell.

Demsetz, Harold. 1997. "Profit Maximization and Rational Behavior," in idem. The Economics of the Firm: Seven Critical Commentarities. Cambridge: Cambridge University Press.

Dosi, Giovanni. 2000. Innovation, Organization, and Economic Dynamics: Selected Essays. Cheltenham: Edward Elgar.

Dosi, Giovanni, Luigi Marengo, and Giorgio Fagiolo. 1996. “Learning in Evolutionary Environments," IIASA, Working Paper.

Dosi, Giovanni, Richard R. Nelson and Sidney G. Winter. 2000. The Nature and Dynamics of Organizational Capabilities. Oxford: Oxford University Press.

Egidi, Massimo. 2000. “Biases in Organizational Behavior,” unpublished paper. 
Foss, Nicolai J. 1996. "Knowledge-Based Approaches to the Theory of the Firm: Some Critical Comments". Organization Science 7: 470-476.

Foss, Nicolai J. 1997. Resources, Firms, and Strategies. Oxford: Oxford University Press.

Foss, Nicolai J. 1998. “The Competence-Based Approach: Veblenian Ideas in the Modern Theory of the Firm", Cambridge Journal of Economics 22: 479-496.

Foss, Nicolai J. 2001. "Bounded Rationality in the Economics of Organization: Present Use and Future Possibilities," Journal of Management and Governance 5: 401-425.

Foss, Kirsten and Nicolai Foss. 2000. "Competence and Governance Perspectives: How Do They Differ? And How Does It Matter?," in Nicolai J. Foss and Volker Mahnke, eds. Competence, Governance, and Entrepreneurship. Oxford: Oxford University Press.

Fransman, Martin. 1994. "Information, Knowledge, Vision and Theories of the Firm," in Giovanni Dosi, David J. Teece and Josef Chytry, eds. 1998. Technology, Organization, and Competitiveness. Oxford: Oxford University Press.

Grant, Robert. 1996. “Toward a Knowledge-Based Theory of the Firm," Strategic Management Journal 17: 109-122.

Heath, C., Mark Knez and Colin Camerer: 1993: “The Strategic Management of the Entitlement Process in the Employment Relationship", Strategic Management Journal 14: 75-93.

Langlois, Richard N. 1992. "Transaction Cost Economics in Real Time," Industrial and Corporate Change 1: 99-127.

Langlois, Richard N. 1999. "Rule-Following, Expertise, and Rationality: A New Behavioral Economics?," in Kenneth Dennis, ed., Rationality in Economics: Alternative Perspectives. Dordrecht: Kluwer Academic Publishers.

Machlup, Fritz. 1946. "Marginal Analysis and Empirical Research," American Economic Review 36: 519-554.

Marschak, Jacob and Roy Radner. 1972. The Theory of Teams. New Haven: Yale University Press.

Marengo, Luigi, Giovanni Dosi, Paolo Legrenzi and Corrado Pasquali. 2000. "The Structure of Problem-Solving Knowledge and the Structure of Organizations," Industrial and Corporate Change 9: 757- 788.

Meyer, Martin. 2001. "Nelson and Winter's Evolutionary Theory - A Citation Analysis," Unpublished Paper.

Nelson, Richard R. and Sidney G. Winter. 1982. An Evolutionary Theory of Economic Change. Cambridge, MA: The Belknap Press.

Nelson, Richard R. and Sidney G. Winter. 2002. “Evolutionary Theorizing in Economics," Journal of Economic Perspectives 16: 23-46.

Newell, Allan and Herbert A. Simon. 1972. Human Problem Solving. Englewood Cliffs: Prentice-Hall.

Nightingale, Paul. 2002. "If Nelson and Winter Are Only Half Right About Tacit Knowledge, Which Half? A Searlean Critique of 'Codification'," forthcoming in Industrial and Corporate Change. 
Pierce, J. Lamar, Christopher S. Boerner, and David J. Teece. 2002. “The Evolutionary Theory in Dynamic Capabilities," fortcoming, Industrial and Corporate Change.

Richardson, George B. 1972. "The Organisation of Industry," Economic Journal 82: 883896.

Sanchez, Ron. 2001. "Resources, Dynamic Capabilities, and Competences: Building Blocks of Integrative Strategy Theory," in Tom Elfring and Henk Volberda, editors Rethinking Strategy, Thousand Oaks, CA: Sage Publications.

Selten, Reinhardt. 1990. “Bounded Rationality," Journal of Institutional and Theoretical Economics 146: 649-658.

Simon, Herbert A. 1947. Administrative Behavior. New York: Macmillan.

Simon, Herbert A. 1955, “A Behavioral Model of Rational Choice,” Quarterly Journal of Economics

Simon, Herbert A. 1982. Models of Bounded Rationality. Cambridge, MA: MIT Press.

Simon, Herbert A. 1985. "Human Nature in Politics," American Political Science Review 79: 293-304.

Teece, David J., and Gary Pisano. 1994. The Dynamic Capabilities of Firms: an Introduction, Industrial and Corporate Change 3: 537-556.

Warglien, Massimo. 1995. "Hierarchical Selection and Organizational Adaptation," Industrial and Corporate Change 4: 161-186.

Williamson, Oliver E. 1985. The Economic Institutions of Capitalism. New York: The Free Press.

Williamson, Oliver E. 1996. The Mechanisms of Governance. Oxford: Oxford University Press.

Williamson, Oliver E. 2000. "Strategy Research: Competence and Governance Perspectives," in Nicolai J. Foss and Volker Mahnke, eds. Competence, Governance, and Entrepreneurship. Oxford: Oxford University Press.

Winter, Sidney G. 1964a. "Economic 'Natural' Selection and the Theory of the Firm," Yale Economic Essays 4: 225-272.

Winter, Sidney G. 1964b. "Review of Richard Cyert and James G. March, A Behavioral Theory of the Firm" American Economic Review 54: 144-148.

Winter, Sidney G. 1986. "The Research Program of the Behavioral Theory of the Firm: Orthodox Critique and Evolutionary Perspective," in Benjamin Gilad and Stanley Kaish, eds. 1986. Handbook of Behavioral Microeconomics, Vol. A. Greenwich: JAI Press.

Winter, Sidney G. 1991. "On Coase, Competence, and the Corporation," in Oliver E. Williamson and Sidney G. Winter, eds. 1991. The Nature of the Firm: Origins, Evolution, and Development. Oxford: Basil Blackwell.

Zandt, Timothy Van. 1998. "Organizations with an Endogenous Number of Information Processing Agents," in M. Majumdar (ed.), Organizations with Incomplete Information, Cambridge, UK: Cambridge University Press. 